\title{
Konjac Biomolecules Assisted-Rod/ Spherical Shaped Lead Nano Powder Synthesized by Electrolytic Process and Its Characterization Studies
}

\author{
T. Theivasanthi ${ }^{1} *$, M. Alagar ${ }^{1}$
}

'Centre for Research and Post Graduate Department of Physics, Ayya Nada Janaki Ammal College, Sivakasi - 626124, Tamilnadu, India.

* Corresponding author: theivasanthi@pacrpoly.org

Tel/fax.: +91-9245175532

\begin{abstract}
Synthesis and structural characterization of $\mathrm{Pb}$ nanoparticles by electrolysis using a bioactive compound-konjac aqueous extract is the main aim of this study. This method is a unique, novel, low cost and double-step procedure with good reproducibility and has not been used for nanoparticles preparation so far. Konjac extract has been added to prevent the oxidation of $\mathrm{Pb}$ nanoparticles. Also the synthesized nanoparticles have been dried in open air to observe their stability. Various types of characterization tools have been utilized to study characters of the end product. Anti-bacterial Studies has also been done. After completion of synthesis process that we have made an attempt to change the shape of the synthesized nanoparticles by the influence of sunbeams and to find the effects of the sunlight on nanomaterials.
\end{abstract}

Keywords: XRD, Lead nanopowder, Konjac, Electrolysis, Debye-Scherer

Citation: T. Theivasanthi and M. Alagar. Konjac biomolecules assisted-rod/spherical shaped lead nano powder synthesized by electrolytic process and its characterization Studies. Nano Biomed. Eng. 2013, 5(1), 11-19.

DOI: $10.5101 /$ nbe.v5i1.p11-19.

\section{Introduction}

Nanoparticles are being synthesized in various methods including electrolysis and many irradiation methods such as sonochemical [1], UV or vis photoirradiation [2], laser pulse [3] and $\gamma$-irradiation methods [4] and so forth. When nanomaterials interact with biological systems, their properties are changed significantly, affecting their functionality and behavior. While, on contact with a biological fluid they may become coated with proteins and other biomolecules. The potential interactions of nanoparticles with biological systems may also be desirable characters in sometimes.

Solvent, $\mathrm{pH}$ value, photo-sensitizer, the concentration and category of stabilizer, irradiation intensity, wavelength, and irradiation time are all important factors that must be considered for shape and size controlled synthesis of metal nanoparticles [5]. In photochemical reduction, hydrated electrons or free organic radicals formed by photo-irradiation (e.g., by UV or visible light) reduces the metal ions to metals. The photolysis of phenols in aqueous solution produces hydrated electrons. Photo-initiators like phenolic compounds absorb light in the UV-visible region and form reactive intermediates such as free radicals [6]. Methanol is also a photoinitiator, used for such purpose [7]. These intermediates (or hydrated electrons) are serving as a reducing agent and prevents the oxidation of lead nanoparticles.

From earlier reports, gold nanorods have been intensively affected by the wavelength of UV light source and their photon flux [8]; rod like gold particles have been prepared by UV irradiation; Metals have strongly absorb light in the visible region due to surface plasma resonance [9]; the number of surface amino group of dendrimers have a key factor to control the particles with UV irradiation method [10]; stabilization of metal nanoparticles by protein is possible one [11]; proteins can bind to nanoparticles either through free amine groups or cysteine residues in the proteins [12]; and via the electrostatic attraction of negatively charged carboxylate groups in enzymes present in the cell wall of bacteria [13].

Antioxidants are chemical substances that donate electron. The aqueous extract of $A$. campanulatus tuber has more significant antioxidant activity and more reducing power as compared to methanol extract [14]. $46.33 \mathrm{mg} \mathrm{g}^{-1}$ of flavonoidal content, $12.67 \mathrm{mg} \mathrm{g}^{-1}$ of phenolic contents and tannins are present in the air dried 
powder of A.campanulatus tubers [15]. Amorphophallus campanulatus (Roxb.) Blume. ex Decne (Synonym : Amorphophallus paeoniifolius; Araceae) commonly known as Konjac. The tubers contain an active enzyme amylase, amino acids, carbohydrates, saponin etc. Glucomannan is a polysaccharide (hemicelluloses) and a super absorbent present in konjac. Flying powder in konjac is a polyol (natural polymer) used in precipitation of soluble heavy metal ions in wastewater.

Lead nanostructures are attractive materials for its potential applications in lead batteries, catalysis, superconductor and photonic crystal. Earlier study reports that hexagon and flower shaped lead oxide $\left(\mathrm{PbO}_{2}\right)$ are the end product in electrolysis process (anodic oxidation of lead) using lead sheet as anode and distilled water [16]. It is known that $\mathrm{Pb}$ nanoparticles are highly reactive and transfer electron to $\mathrm{N}_{2} \mathrm{O}, \mathrm{O}_{2}$, etc. [17]. While on synthesis of $\mathrm{Pb}$ nanoparticles, increasing the concentration of surfactant/stabilizing agent have produced $\mathrm{Pb}$ hollow nanoparticles and decreasing its concentration have produced solid $\mathrm{Pb}$ nanoparticles [18].

In this study, we will present preparation and structural characterization of $\mathrm{Pb}$ nanoparticles synthesized by electrolysis using a bioactive compound-konjac aqueous extract as stabilizing agent to prevent from oxidation. Our method is a unique, novel and double-step procedure with good reproducibility. To our knowledge, such a procedure has so far not been used for nanoparticles preparation. Also, we have made an attempt to find the effects of the sunlight on nanomaterials and got morphologically changed-rod like $\mathrm{Pb}$ nanoparticles.

It explicates that the sunlight can be utilized for dual function i.e. as a dryer for the synthesized materials and as a morphological changer. We found the shape of the konjac extract added $\mathrm{Pb}$ nanoparticles changed to rod shape by the influence of sunbeams. It is pertinent to note that we have made these morphological changes after completion of the entire synthesis process. Avoiding oxidation is the main challengeable task while on metal nanoparticles preparation particularly in $\mathrm{Pb}$ nanoparticles synthesis. Drying $\mathrm{Pb}$ nanoparticles in open air and sunlight indicates that this task is defeated/achieved by adding konjac extract.

\section{Experimental method}

The experiment was performed in an electrochemical bath (volume: $4 \times 3 \times 3 \mathrm{~cm}^{3}$ ) with two electrode set up. High purity lead rod was utilized as working electrode (anode), stainless steel rod as counter electrode (cathode) and $3 \mathrm{~cm}$ distance was kept between the electrodes. $5 \mathrm{~g}$ of $\mathrm{Pb}\left(\mathrm{NO}_{3}\right)_{2}$ salt was kept in a clean glass vessel. $100 \mathrm{~mL}$ of distilled water was poured in this vessel and stirred well until the lead nitrate salt was completely dissolved in the water (clear and colourless solution). This solution was transferred to the electrochemical bath and used as an electrolyte. A constant voltage of $15 \mathrm{~V}$ was applied between the electrodes using a power supply for a time span of 10 minutes. This process is shown in Figure 1. At the end of the process, deposition of $\mathrm{Pb}$ nanoparticles was observed and they were removed from the cathode and the $\mathrm{Pb}$ nanoparticles (settled down on the electrolytic cell) were also removed from the bath. The electrolyte $\mathrm{Pb}\left(\mathrm{NO}_{3}\right)_{2}$ is an oxidizing agent. The $\mathrm{Pb}$ nanoparticles are highly reactive material and they can be easily oxidized. So, the stabilization of lead nanoparticles is essential.

For making konjac aqueous extract, $20 \mathrm{~g}$ of konjac tuber was sliced/cut into many pieces. These pieces were put in a vessel and a $100 \mathrm{~mL}$ of distilled water poured in it. This vessel was kept in a stove and boiled for 10 minutes. At the end, konjac pieces were separated and the konjac aqueous extract was decanted. A few drops of Konjac extract (stabilizing agent) was added to the synthesized $\mathrm{Pb}$ nanoparticles and were kept in a hot air oven at $50{ }^{\circ} \mathrm{C}$ for two hours/until it dried. After completion of drying process, their appearance was very fine and powdery in nature. Their structural characterizations were studied and results confirmed the formation of lead nanopowder (with spherical shaped particles). To get rod shaped $\mathrm{Pb}$ nanoparticles (to change the spherical shape to rod shape), the same synthesis procedures were adopted and dried in sunlight instead of drying in hot air oven (Model: HASTHAS oven with size $355 \mathrm{~mm} \times 355 \mathrm{~mm} \times 355 \mathrm{~mm}$ and max. temp. $300^{\circ} \mathrm{C}$ ).

The X-Ray Diffraction (XRD) analysis of the prepared sample of $\mathrm{Pb}$ nanoparticles was done using a X'pert PRO of PANalytical diffractometer, $\mathrm{Cu}-\mathrm{K} \alpha$ X-rays of wavelength $(\lambda)=1.5406 \AA$ and data was taken for the $2 \theta$ range of $10^{\circ}$ to $80^{\circ}$ with a step of $0.0170^{\circ}$. The surface morphology was analyzed by using SEM (JEOL Model JSM-6360). The particle size of the Pb nanoparticles was analyzed by Dynamic Light Scattering method using particle size analyzer (Malvern Zetasizer nanosizer). TEM coupled with EDS (Model-ZEISS) was used to analyze the outer surface and inner structures of the particles. Thermal studies of the sample were analysed by Diffrential Scanning Calorimetry (DSC). Concentration of the sample was analyzed by Atomic absorption spectrophotometer (model SHIMADZU-AA 6300). Functional groups were analyzed by SHIMADZU FT-IR spectrometer. The antibacterial activities of $\mathrm{Pb}$

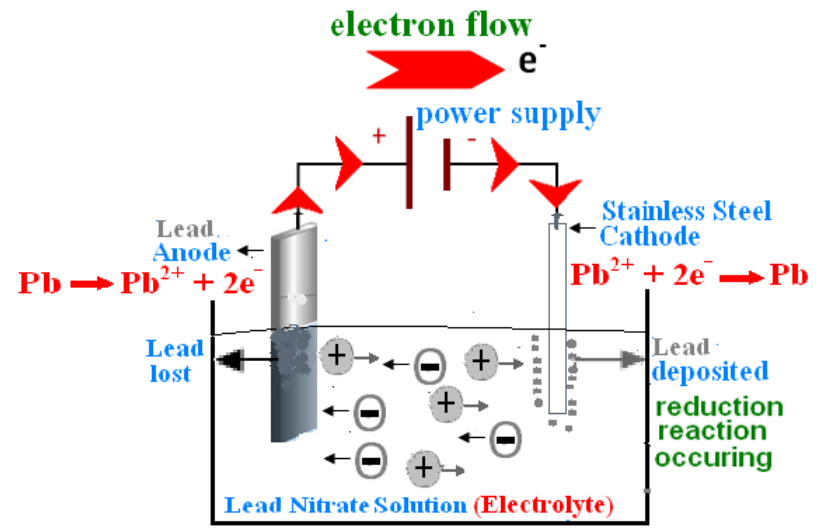

Figure 1 Schematic Diagram-Electrolysis of $\mathrm{Pb}\left(\mathrm{NO}_{3}\right)_{2}$ Solution. 
nanoparticles were studied against Escherichia coli by Cup and Plate method. Standard Zone of Inhibition (ZOI) was measured and evaluated from this microbiology assay.

\section{Results and discussions}

\subsection{XRD studies-peak indexing-Pb nanorods}

The XRD pattern of the lead nanorods synthesized by electrolysis method is shown in Figure 2. A number of strong Bragg reflections can be seen which correspond to the (111), (200), (220) (311), (222) and (400) reflections of Face Centered Cubic symmetry (FCC) lead. There is no any spurious diffraction peak found in the sample. The high intense peak for FCC materials is generally (111) reflection; all even or all odd number in each $\mathrm{h}, \mathrm{k}, \mathrm{l}$; both of these facts are observed in the prepared sample. The intensity of peaks reflects the degree of crystallinity and broadening in diffraction peaks indicates very small size of crystallite [19]. The $\mathrm{Pb}$ nanoparticles XRD reflects that the formed lead nanoparticles are crystalline and broad diffraction peaks indicate very small size crystallite. The size of the $\mathrm{Pb}$ nanoparticles estimated from DebyeScherrer formula (Instrumental broadening) is $8 \mathrm{~nm}$.

A good agreement between the Experimental diffraction angle [2 $\theta$ ] and Standard diffraction angle [2 $\theta$ ] of specimen is confirming standard of the specimen. $2 \theta$ values of all the observed six peaks have been compared with the standard powder diffraction card of Joint Committee on Powder Diffraction Standards (JCPDS), lead file No. 65-2873. The d-spacing values of experimental is also confirming to the standard values. The XRD study confirms/indicates that the resultant particles are (FCC)

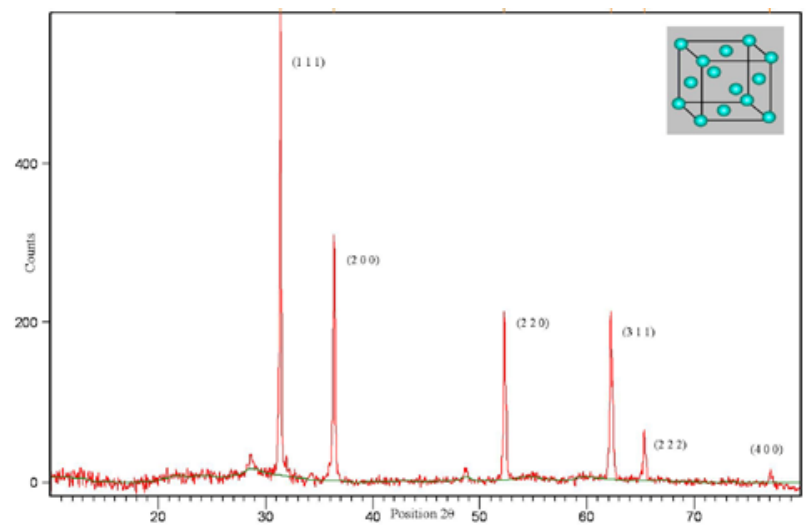

Figure 2 XRD showing Peak Indices \& $2 \theta$ Positions. lead nanopowder.

\subsection{XRD-lattice constant and particle size calculation}

The theoretical value of unit cell edges ' $a$ ' using atomic radius, average particle size by Debye-Scherrer formula and d-spacing value (the interplanar spacing between the atoms) by using Bragg's Law are calculated. The results are presented in the Table.1. FCC crystal structure of lead has unit cell edge ' $a$ ' $=4.9497 \AA$ (For lead $\mathrm{r}=0.175 \mathrm{~nm}$ ). The experimental lattice constant ' $a$ ' is calculated from the most intense peak (111) of the XRD pattern is 4.938 $\AA$. Both theoretical \& experimental lattice constant ' $a$ ' are in agreement. The unit cell volume calculated from experimental ' $a$ ' is $120.4074 \AA^{3}$.

\subsection{XRD-instrumental broadening}

When particle size is less than $100 \mathrm{~nm}$, appreciable broadening in XRD lines will occur because of particle size and strain. The observed line broadening will be used to estimate the average size of the particles. The total broadening of the diffraction peak is due to sample and the instrument. The average particle size D and the strain $\varepsilon$ of the experimentally observed broadening of several peaks will be computed simultaneously using least squares method. Ghosh et al. in their report, due to the size effect, the peaks broaden and then widths become larger as the particle size becomes smaller. The broadening of the peak may also occur due to micro strains of the crystal structure arising from defects like dislocation and twinning [20]. Williamson and Hall plot is plotted with $\sin \theta$ on the $\mathrm{x}$-axis and $\beta \cos \theta$ on the $\mathrm{y}$-axis (in radians). A linear fit is got for the data. From the linear fit, particle size and strain are extracted from y-intercept and slope respectively. The extracted particle size is $8 \mathrm{~nm}$ and strain is 0.0021 .

\subsection{XRD-dislocation density and theoretical density}

The dislocation density is defined as the length of dislocation lines per unit volume of the crystal [21]. Chen and Hendrickson measured and determined dislocation density and hardness of several silver crystals. They found that crystals with larger dislocation density were harder [22]. It has been shown for different pure face-centered cubic (fcc) metals processed by Equal Channel Angular Pressing (ECAP) that the dislocation density increases

Table 1 XRD data of lead nanopowder

\begin{tabular}{|c|c|c|c|c|c|c|c|}
\hline \multicolumn{9}{|c|}{ Experimental Lead } & \multicolumn{2}{c|}{$\begin{array}{c}\text { Stand Lead JCPDS: } \\
65-2873\end{array}$} \\
\hline $\begin{array}{c}2 \theta \text { of peaks } \\
(\mathrm{deg})\end{array}$ & hk1 & $\begin{array}{c}\text { FWHM }(\beta) \\
\text { radians }\end{array}$ & $\begin{array}{c}\text { Particle Size } \\
\text { nm }\end{array}$ & $\begin{array}{c}\text { d-spacing } \\
\AA\end{array}$ & $\begin{array}{c}\text { Lattice Constant (a) } \\
\AA\end{array}$ & $\begin{array}{c}2 \theta \text { of peaks } \\
\text { (deg) }\end{array}$ & $\begin{array}{c}\text { d-spacing } \\
\AA\end{array}$ \\
\hline 31.3777 & $(111)$ & 0.00291 & 49 & 2.85096 & 4.938 & 31.2867 & 2.8574 \\
\hline 36.3611 & $(200)$ & 0.00321 & 45 & 2.47086 & 4.942 & 36.2828 & 2.4746 \\
\hline 52.3101 & $(220)$ & 0.00233 & 66 & 1.74894 & 4.947 & 52.2506 & 1.7498 \\
\hline 62.2696 & $(311)$ & 0.00584 & 28 & 1.49102 & 4.945 & 62.1757 & 1.4922 \\
\hline 65.3477 & $(222)$ & 0.00584 & 28 & 1.42804 & 4.947 & 65.2722 & 1.4287 \\
\hline 77.0153 & $(400)$ & 0.00712 & 25 & 1.23719 & 4.949 & 77.0311 & 1.2373 \\
\hline
\end{tabular}


while grain size decreases with increasing strain and ultimately these parameters reach saturation values [23]. Above a certain grain size limit $(\sim 20 \mathrm{~nm})$ the strength of materials increases with decreasing grain size [24]. The dislocation density $(\delta)$ in the sample has been determined using values of FWHM, $\theta$, lattice constant and particle size [25]. The dislocation density can also be calculated with crystallite size value [26]. Both of these methods give approximately same results. The number of unit cell is calculated from crystallite size and cell volume of the sample [27].

From the calculated values of dislocation density and number of unit cells, it is observed that dislocation density is indirectly proportional to particle size and number of unit cell. Dislocation density increases while both particle size and number of unit cell decreases. On the other side, particle size increases while number of unit cell increases. The average dislocation density of lead nanoparticles found to be as $11.1 \times 10^{14} \mathrm{~m}^{-2}$. The dislocation density of electrolyzed silver nanoparticles $9.2 \times 10^{14} \mathrm{~m}^{-2}$ has been noted from our earlier report [28]. It is observed that the sample lead nanoparticles harder than electrolyzed silver nanoparticles.

Theoretical density of the sample was calculated as per earlier report [29]. The mass of one unit of the chemical formula- $\mathrm{Pb}(\mathrm{M}=207.8 \mathrm{amu})$, the number of such chemical units in one unit cell $(Z=4)$, the volume of the crystalline unit cell as determined by XRD (V = $\left.120.4074 \AA^{3}\right)$ and the Avagadro's number $(\mathrm{N}=6.0221$ $\times 10^{23}$ ). Using the above values, the theoretical density has been calculated and the value is $11.461 \mathrm{~g} \mathrm{~cm}^{-3}$. It is agreed well with the reported data.

\subsection{XRD-crystallinity index and morphology index}

Sharper XRD peaks are typically indicative of high nanocrystalline nature and larger crystallite materials. From our XRD data, a peak broadening of the nanoparticles is noticed and average particle size, is calculated as $8 \mathrm{~nm}$. TEM result indicates particle size is $10 \mathrm{~nm}$. Crystallinity Index (Icry) is evaluated by comparison of XRD crystallite size and TEM particle size. Xubin et al. in their report, if Icry value is close to 1 , then it is assumed that the crystallite size represents monocrystalline whereas a polycrystalline have a much larger crystallinity index [30]. The Icry of the sample is 1.25 which is more than 1.0. It indicates that the sample lead nanoparticles are highly crystalline and fcc phase structure is well-indexed.

It is well known that lead powder is widely used in many diverse industries such as scientific, nuclear Oil \& gas exploration, anti-corrosive paints, lubricating, and sinter materials, catalysts, explosives industries and also in medical, electrical fields. The use of lead nanopowder is derived from its unique structural, physical and chemical properties, which are reflected by its hardness, surface properties, particle size and morphology. The specific surface area of lead nanopowder (which is important to many of the above mentioned industries) is dependent on the interrelationship of particle morphology and size. Morphology Index (MI) is calculated from FWHM of XRD data, based on our earlier report [31]. Sample lead nanopowder, (MI) range is from 0.50 to 0.75 . It is correlated with the particle size (range from 25 to 66 $\mathrm{nm}$ ) and specific surface area (range from 5.567 to 14.239 $\mathrm{m}^{2} \mathrm{~g}^{-1}$ ). It is observed that MI has direct relationship with particle size and an inverse relationship with specific surface area.

\subsection{SEM \& TEM analyses Pb nanoparticles}

The SEM \& TEM images have shown the result in Figure.3. The images reveal about the changed shape i.e. rod shaped $\mathrm{Pb}$ nanoparticles. The length to diameter ratio from SEM analysis; largest rod is 10 and smallest rod is 5. These ratio $<20$ indicates rod shape. An attempt has been made to change the shape of $\mathrm{Pb}$ nanoparticles (konjac extract added) from spherical to rod by the influence of sunbeams. $\mathrm{Pb}$ nanoparticles strongly absorb light in the visible region due to Surface Plasmon Resonance (SPR). The absorbed light promotes the reactions/effects of the sunlight on $\mathrm{Pb}$ nanoparticles, in presence of the amino group of konjac aqueous extract which elongates the nanoparticles in one direction and change their shape from spherical to rod.

The result explicates that it is possible to change the shape even after completion of the entire synthesis process. The SEM image in Figure 3(a) shows some spherical particles among the lead nanorods which indicates that these rods have been made up of spherical particles (nucleation growth of particles). The rods have been formed by the binding of spherical particles one by one (one over one) and have been elongated in one direction after binding. Due to this, some up and down structures are in the outer surfaces of the nanorods. The surfaces (textures) are not uniform and not smooth.

The synthesized nanorods are in various sizes. The length is varying from $0.5 \mu \mathrm{m}$ to $12 \mu \mathrm{m}$ and diameter is $0.1 \mu \mathrm{m}$ to $1.25 \mu \mathrm{m}$. It has been considered to calculate, the average size between smallest rod and largest rod, to ascertain the size of nanorod. The length of largest rod is $12 \mu \mathrm{m}$ and diameter is $1.25 \mu \mathrm{m}$. The length of smallest rod is to $0.5 \mu \mathrm{m}$ and diameter is to $0.1 \mu \mathrm{m}$. The average length of rod is to $6.25 \mu \mathrm{m}$ and diameter is to $0.675 \mu \mathrm{m}$. However, SEM analysis does not give real image and it gives real shape only. The above estimated average size of rod is not exact one and it is possible from TEM analysis only.

It is apparently that the diameter of the smallest rod is equal to the diameter of spherical particle because the rods have been grown by nucleation growth of smaller particles. It is compared, the diameter of the smallest rod $(0.1 \mu \mathrm{m})$ from SEM image with particle diameter (10 $\mathrm{nm}$ ) from TEM image. From this comparison, it is found that the rod diameter 10 times more than TEM particle 
diameter and the average of the rod has been divided by 10 to assess the real average size of the rod. It is found that the real average length of rod is $625 \mathrm{~nm}$ and diameter is $67 \mathrm{~nm}$. This observed value $67 \mathrm{~nm}$ corroborates with the particle size-diameter $66 \mathrm{~nm}$ from (220) indexed peak of XRD. Also, it is close to the rod diameter $55 \mathrm{~nm}$ calculated by particle size analyzer.

HRTEM pictures of the synthesized lead nanoparticles have been shown in Figure 3(b). It shows the diameter of the particle is approximately $10 \mathrm{~nm}$. Selected Area Electron Diffraction (SAED) pattern has been taken over 200 micron (diameter) condenser aperture is in Figure 3(c). This indexed SAED pattern confirms FCC structure of the lead. SAED ring pattern is similar to XRD DebyeScherrer pattern. It provides information about the crystal structure and lattice spacing of the sample; however this information will not be as accurate as from XRD. Figure 3(d) shows the d-spacing $2.83 \AA$ which is well agreement with XRD d-spacing $2.85 \AA$ of (111) indexed, most intense peak at $2 \theta 31.37$.

\subsection{Specific surface area}

The surface states will play an important role in the nanoparticles, due to their large surface to volume ratio with a decrease in particle size [32]. Specific surface area (SSA) is a material property. It is a derived scientific value that can be used to determine the type and properties of a material. It has a particular importance in case of adsorption, heterogeneous catalysis and reactions on surfaces. SSA is the SA per mass. Jiji et al. has used the values of particle Surface Area, volume and density for the calculation of specific surface area [33]. Yo-Jong et al. has calculated the specific surface area of spherical shaped particle in another method using particle size (Dp) and density $\rho$ of $\mathrm{Pb} 11.461 \mathrm{~g} \mathrm{~cm}^{-3}$ [34]. Mathematically, SSA can be calculated using these formulas. Both of these formulas yield same result. $S=4 \times 10^{3} / D_{p} \rho$ is the equation
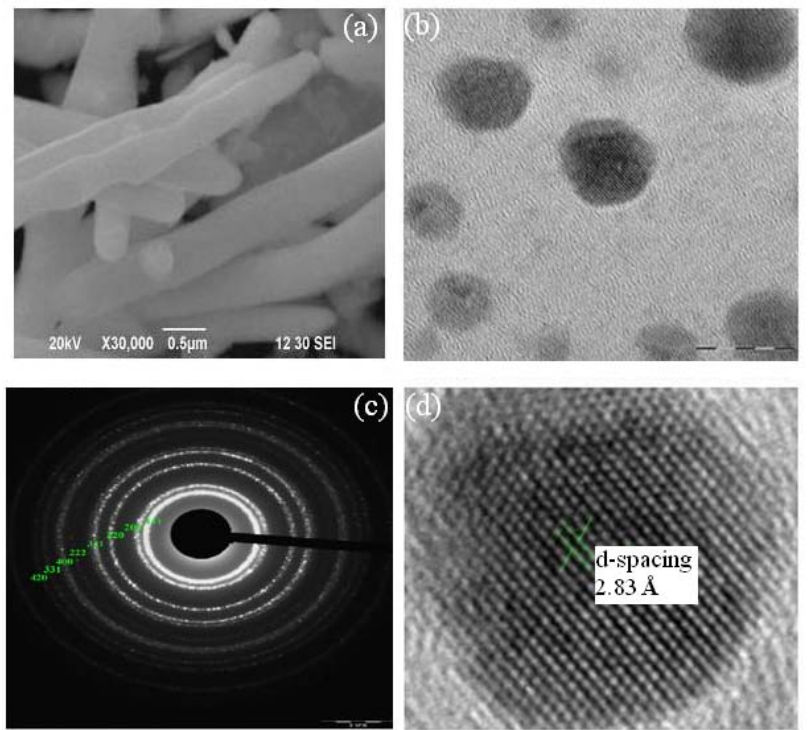

Figure 3 SEM and TEM Images. (a) Pb Nanorods at 30000 magnification. (b) HRTEM-Pb Nanospherical. (c) SAED Image-Pb Nanospherical. (d) d-Spacing of $\mathrm{Pb}$ Nanospherical
Table 2 (a) Specific surface area of lead nanorods and nanosphericals

\begin{tabular}{|c|c|c|c|c|c|c|}
\hline \multicolumn{2}{|c|}{ Particle size (nm) } & $\begin{array}{c}\text { Surface } \\
\text { Area } \\
\left(\mathrm{nm}^{2}\right)\end{array}$ & $\begin{array}{c}\text { Volume } \\
\left(\mathrm{nm}^{3}\right)\end{array}$ & $\begin{array}{c}\text { Density } \\
\left(\mathrm{g} \mathrm{cm}^{-1}\right)\end{array}$ & $\begin{array}{c}\text { SSA } \\
\left(\mathrm{m}^{2} \mathrm{~g}^{-1}\right)\end{array}$ & $\begin{array}{c}\text { S A to } \\
\text { volume } \\
\text { ratio }\end{array}$ \\
\hline 625 & 67 & 139693 & 2236540 & 11.461 & 5.4497 & 0.0624 \\
\hline- & 10 & 314.15 & 523.59 & 11.461 & 52.35 & 0.53 \\
\hline
\end{tabular}

for calculation of SSA of rod shaped particles The nanorod length and diameter estimated by SEM analysis has been used to calculate SSA and details are in Table 2.

The equations for the calculation of lattice constant, particle size, instrumental broadening, dislocation density, theoretical density, crystallinity index, morphology index and specific surface area are in our earlier report [28], presented in other reports as per the references as well as in the supplementary file.

\subsection{EDS analyses of Pb nanoparticles}

The energy value of each peak is matched with X-ray emission wavelength for non-diffractive analysis. The EDS analysis results spectrum of lead is shown in Figure 4(a). It gives distinct elemental signals of lead. The quantitative analysis of lead in weight $\%$ abundance is shown Figure 4(b). EDAX analysis is also in well agreement with XRD report and TEM report which indicating that $100 \%$ of lead.

\subsection{Particle size analyses of $\mathrm{Pb}$ nanorods}

The particle size analysis report from DLS experiment is further corroborated the rod shape of $\mathrm{Pb}$ nanoparticles. Generally, rod shaped particles will not go under Brownian motion or their motion will too slow to measure and this fact was observed from this analysis. $\mathrm{As}$ the $\mathrm{Pb}$ nanoparticles were in rod shape, there was no Brownian motion and the size distribution by intensity peak was unable to be measured/seen using this DLS analysis. However, this analysis gives average particle size as $55 \mathrm{~nm}$ (Z-Average-d.nm is $1.020 \mathrm{e}^{4}$ ) and Poly Dispersity Index (PDI) as 0.966. The observed rod size (diameter $55 \mathrm{~nm}$ ) is close to the rod size (diameter 49 $\mathrm{nm}$ ) most intensity (111) peak of XRD. Konjac aqueous extract (bio-polymer) was added to the synthesized lead nanoparticles as stabilizer. PDI 0.966 is observed from this analysis, which indicates the bio-polymer (konjac aqueous extract).

\subsection{DSC analyses of $\mathrm{Pb}$ nanorods}

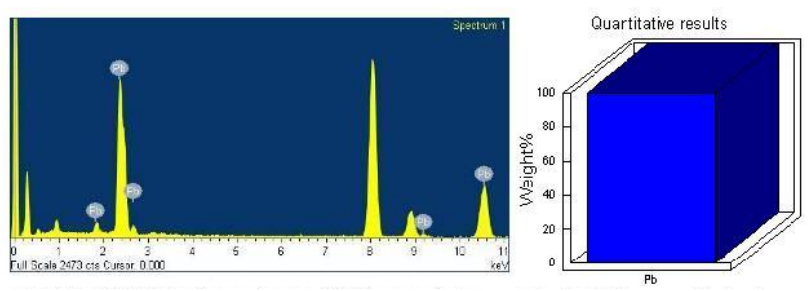

Figure 4 (a). EDAX Spectrum Showing Pb Nanoparticles (b). Elements $\%$ Analyses. 
The DSC analysis report of the sample is shown in Figure 5. The onset at $326.36{ }^{\circ} \mathrm{C}$ is the melting point which is well agreement with bulk lead $\left(327^{\circ} \mathrm{C}\right)$ and lead nanoparticles of earlier report [35]. This confirms that the synthesized sample is lead nanoparticles and its purity. However, the sample have some more peaks other than peak at $327{ }^{\circ} \mathrm{C}$ and earlier report has one peak at 327 ${ }^{\circ} \mathrm{C}$ which differentiate between both of these analysis. The more peaks which are due to the small layer of Konjac extract over the sample. Very small peak heights and broaden size (width) of these peaks are indicating that Konjac extract covers only a small layer over the sample. The downward movement of the peak in DSC heating curve indicates that the peak is endothermic peak. The Surface Area has been calculated as 6.5624 $\mathrm{J} \mathrm{g}^{-1}$ and this positive value indicates that the observed peak is endothermic peak. The melting peak in $327.21^{\circ} \mathrm{C}$ appears almost as a straight line and increasingly sharper. The straight line and sharpness of melting peak show the purity as well as the smaller size of the synthesized sample.

\subsection{AAS analyses of $\mathrm{Pb}$ nanorods}

The synthesized lead nanoparticles have been analysed by AAS with optics parameter settings $\mathrm{Pb}$ wavelength $283.3 \mathrm{~nm}$ and air-acetylene $\left(\mathrm{C}_{2} \mathrm{H}_{2}\right)$ flame type. A calibration curve diagram for Concentration of lead nanoparticles in Parts per Million (ppm) Vs Absorbance has been drawn and a linear fit has been get. It is observed from the Figure. 6 that the absorbance is directly proportional to the concentration. The linear fit indicates that the lead nanoparticles have been distributed in proper proportion. Concentration of the sample is $6.9006 \mathrm{ppm}$ (6.9006 $\mathrm{mg} \mathrm{L}^{-1}$ ) and absorbance is 0.1298 . Absorbance to concentration ratio of the standard at $4 \mathrm{ppm}$ concentration is 0.01880 and for sample is 0.01880 . Both the value is same. Likewise, concentration to absorbance ratio of the standard at 4 ppm concentration is 53.1635 and for sample are 53.1633. It indicates high purity of the sample.

\subsection{FT-IR analyses of Pb nanorods}

To demonstrate the Konjac extract bound to the surface of the lead nanoparticle, FTIR analyses were performed. The FT-IR spectrum of lead nanorods is shown in Figure 7. The absorption peak at $462.86 \mathrm{~cm}^{-1}$ indicates the

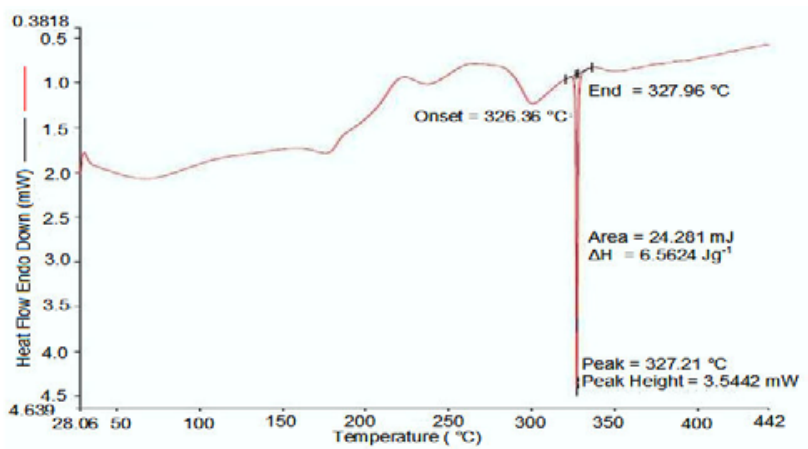

Figure 5 DSC Analysis shows Sharp Peak. presence of lead [36]. The observed wave numbers for amines, amides and amino acids indicate the presence of protein [37]. The amino group is one of the key factors in controlling the $\mathrm{Pb}$ nanoparicles.

The protein material are encapping the metal particles and likely to serve as a capping/stabilizing agent [38]. It is concluded from earlier report $\mathrm{NH} / \mathrm{C}-\mathrm{O}$ groups bind with metals (lead) nanoparticles [39]. Amino acid residues and peptides of proteins have the stronger ability to bind metal and very high affinity to bind with metals. So that protein itself can act as an encapsulating agent and possibly form a layer covering the metal nanoparticles. This layer prevents agglomeration, protects the nanoparticles from agglomerization and thereby stabilizes the medium [40].

The observed bands at wave numbers $3313 \mathrm{~cm}^{-1}$, $3195 \mathrm{~cm}^{-1}, 2362 \mathrm{~cm}^{-1}, 1670 \mathrm{~cm}^{-1}, 1454 \mathrm{~cm}^{-1}, 1400$ $\mathrm{cm}^{-1}, 1334 \mathrm{~cm}^{-1}$ and $1193 \mathrm{~cm}^{-1}$ imply the presence of protein/peptide on the nanoparticle surface. The NH/C-O groups also indicate the presence of biomolecules like nitrates and Carboxylic Acids. C-O-C stretching of wave numbers $1193 \mathrm{~cm}^{-1}, 808 \mathrm{~cm}^{-1}$ and $750 \mathrm{~cm}^{-1}$ indicates polysaccharides. It is noted here that Glucomannan is a water-soluble polysaccharide (hemicelluloses)-straightchain polymer, a super absorbent is present in konjac. Oxidations of the synthesized lead nanoparticles are prevented by polysaccharides which are serving as reducing agent. Chealating compounds sediment the lead nanoparticles from residues.

Phenolic compounds consisting of a hydroxyl group $(\mathrm{OH})$ bonded directly to an aromatic hydrocarbon group. Presence of $\mathrm{OH}$ group (Wave numbers $3313 \mathrm{~cm}^{-1}$ and 750 $\mathrm{cm}^{-1}$ ) along with aromatic compounds indicates phenolic

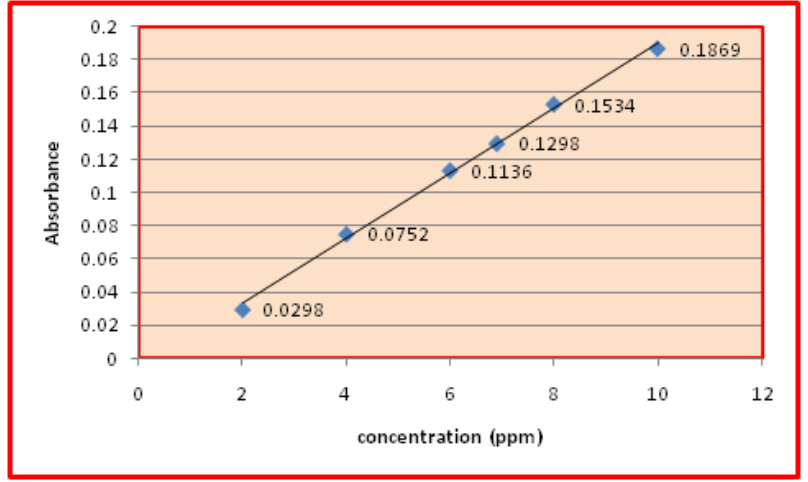

Figure 6 Concentration Vs Absorbance

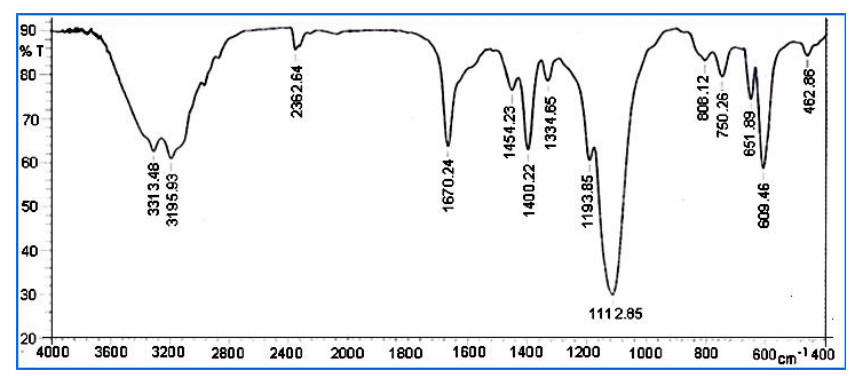

Figure 7 FT-IR Spectrum of Lead Nanorods 
compounds. C-O stretching vibration indicates the secondary alcohol [41]. Presence of alcohol is observed from the wavenumbers $3313 \mathrm{~cm}^{-1}, 1670 \mathrm{~cm}^{-1}, 1400 \mathrm{~cm}^{-1}$, $1334 \mathrm{~cm}^{-1}$ and $750 \mathrm{~cm}^{-1}$ due to $\mathrm{C}-\mathrm{O}$ and $\mathrm{O}-\mathrm{H}$ groups. It is known that $\mathrm{Pb}$ nanoparticles are highly reactive and transfer electron to $\mathrm{N}_{2} \mathrm{O}, \mathrm{O}_{2}$, etc. The synthesized lead nanoparticles, while on transferring electrons to air, photo-initiators like phenolic compounds and alcohols play some roles to prevent such electron transfer. They absorb light and form hydrated electrons to reduce metal ions to metal. It is noted here that the flying powder of konjac is a polyol (natural polymer) which precipitates soluble heavy metal ions in water.

Wave numbers $3313 \mathrm{~cm}^{-1}, 1670 \mathrm{~cm}^{-1}, 808 \mathrm{~cm}^{-1}$ and $750 \mathrm{~cm}^{-1}$ indicate the flavanoids which are antioxidant substances possess reducing power and can donate electrons. They prevent the oxidation of lead nanoparticles. Proteins in the konjac aqueous extract bind to lead nanoparticles through amine and carboxylates (COO- at the wave number $1400 \mathrm{~cm}^{-1}$ and 1334 $\mathrm{cm}^{-1}$ ). Water has been used as solvent in the synthesis process. So that the hydroxyl group $(\mathrm{OH})$ is occurred predominantly (Wavenumbers $3313 \mathrm{~cm}^{-1}, 1400 \mathrm{~cm}^{-1}$, $1334 \mathrm{~cm}^{-1}$ and $750 \mathrm{~cm}^{-1}$ ) which indicates moisture surroundings of nanoparticles. Br-stretching (Wave numbers $750 \mathrm{~cm}^{-1}$ and $651 \mathrm{~cm}^{-1}$ ) indicates that mixing of $\mathrm{KBr}$ with lead nanoparticles for making pellet while FTIR analyses.

\subsection{Anti-bacterial studies of spherical Pb nanoparticles}

Nanomaterials are the leading requirement of the rapidly developing field of nanomedicine, bionanotechnology. Nanoparticles usually have better or different qualities than the bulk material of the same

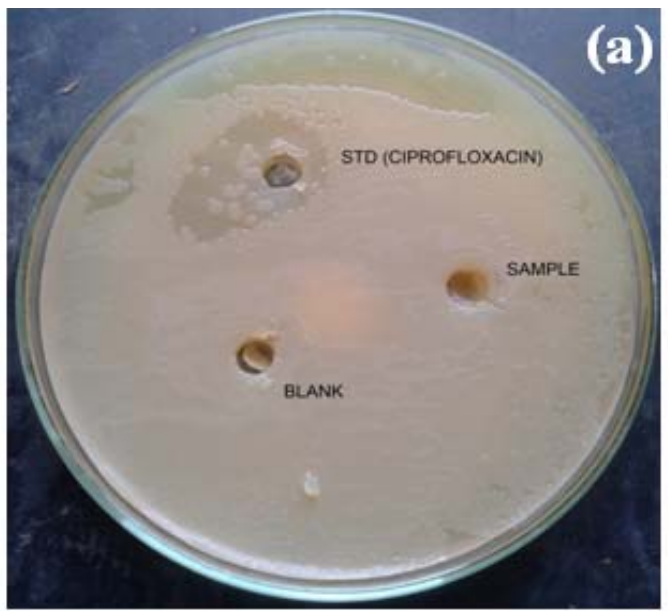

(a)

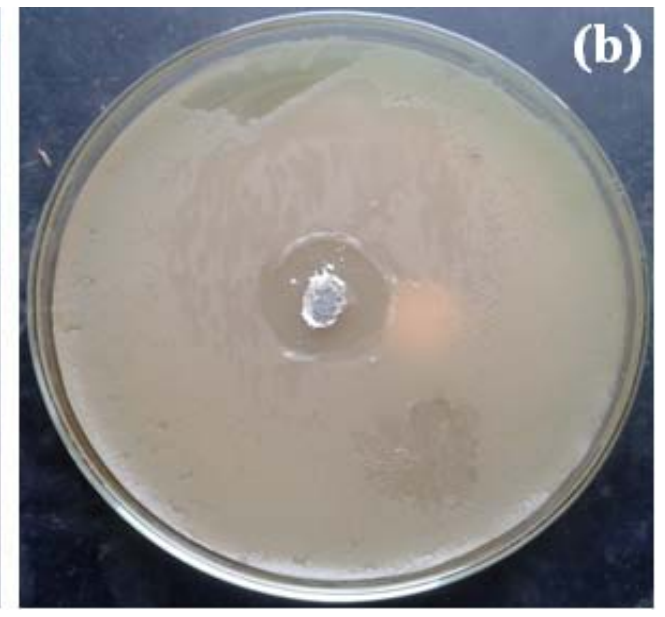

Figure 8 Zone of Inhibition Against E. coli Bacteria. (a) No Zone. (b) A mild zone:5 mm.

Table 3 Comparision of Surface Area to Volume Ratio and antibacterial activities of Lead Nanoparticles on $E$. coli (Gram Negative bacteria)

\begin{tabular}{|c|c|c|c|c|c|c|c|}
\hline $\begin{array}{c}\text { Nano } \\
\text { particles }\end{array}$ & $\begin{array}{c}\text { Particle Size } \\
(\mathrm{nm})\end{array}$ & $\begin{array}{c}\text { Surface Area } \\
\left(\mathrm{nm}^{2}\right)\end{array}$ & $\begin{array}{c}\text { Volume } \\
\left(\mathrm{nm}^{3}\right)\end{array}$ & $\begin{array}{c}\text { Surface Area to } \\
\text { Volume Ratio }\end{array}$ & $\begin{array}{c}\text { SSA } \\
\left(\mathrm{m}^{2} \mathrm{~g}^{-1}\right)\end{array}$ & $\begin{array}{c}\text { Diameter } \\
\text { Inhibition Zone } \\
(\mathrm{mm})\end{array}$ & $\begin{array}{c}\text { E.coli Bacteria } \\
\text { SSA } \\
\left(\mathrm{m}^{2} \mathrm{~g}^{-1}\right)\end{array}$ \\
\hline Lead & 10 & 314.15 & 523.59 & 0.53 & 52.35 & 5 & 20.09 \\
\hline Silver & 24 & 1809 & 7235 & 0.25 & 24 & 12 \\
\hline
\end{tabular}

element and have immense surface area relative to volume. For centuries, People have avoided lead, in their normal life, unlike other metals due its cumulative poison nature. From the preliminary screening anti-bacterial study against E.coli bacteria, it is observed that lead nanoparticles act different from bulk lead, like an inert material and show mild activity when using large quantity but, how this material will act in other biological cells like plants and animals which should be further investigated elaborately.

Antibacterial activities of lead nanoparticles were evaluated by cup and plate method. A concentration of $50 \mathrm{mg} \mathrm{mL}^{-1}$ sample solution was used. Zone of Inhibition (ZOI) was measured from this microbiology assay. Figure 8(a) and 8(b) show the result. The sample shows no antimicrobial activity against $E$. coli when examined using cup and plate method. Mild zone of inhibition of $5 \mathrm{~mm}$ was found when the sample of $20 \mathrm{mg}$ was directly kept on the surface of the plate with E. coli. It is a general fact that using a medicine in proper dose is tolerable one but using it in over dosage sometimes leads to death or undesired effects. Likewise, while using optimal quantity of sample in cup and plate test, E. coli tolerates it and does not show ZOI. A mild ZOI is made while dumping with large quantity of sample $(20 \mathrm{mg})$ on E. coli.

In a solid material, the surface-area-to-volume ratio (SA:V) or Specific Surface Area (SSA) is an important factor for the reactivity that is, the rate at which the chemical reaction will proceed. Materials with large SA: $\mathrm{V}$ (very small diameter) reacts at much faster rates than monolithic materials, because more surfaces are available to react.

For studying, changes in Specific Surface Area (SSA) of nanoparticles and its effects on antibacterial 
activities nanoparticles, we have compared SSA of lead nanoparticles and silver Nanoparticles of our earlier study [28]. The details are presented in Table 3. Our earlier study suggests that that increased SSA results enhance the antibacterial activities of Silver nanoparticles. From this comparative study, though lead nanoparticles have SSA more than silver nanoparticles, the antibacterial activities of lead nanoparticles is less than Silver nanoparticles. It indicates that the reactions of nanoparticles with bacterial cell wall/fluid are also the determining factor of antibacterial activities.

We have made an attempt to study the SSA of bacteria and its reactivity to antibacterial activities of nanoparticles. For this study, we have compared SSA of $E$. coli with nanoparticles of lead and silver. E. coli details (Cell length: $2 \times 10^{-6} \mathrm{~m}$, diameter: $0.8 \times 10^{-6} \mathrm{~m}$, total volume: $1 \times 10^{-18} \mathrm{~m}^{3}$, surface area: $6 \times 10^{-12} \mathrm{~m}^{2}$, wet weight: $1 \times 10^{-12} \mathrm{~g}$, dry weight: $3.0 \times 10^{-13} \mathrm{~g}$ ) has been extracted from The CyberCell Database-CCDB and SSA calculated accordingly [42].

Bacteria, viruses and fungi all depend on an enzyme to metabolize oxygen to live. Silver interferes with the effectiveness of the enzyme and disables the uptake of oxygen, thereby killing the microbes but in the case of lead, it does not interfere with the enzyme or showing less interference at high concentration. It is observed from our earlier study of silver nanoparticles that SSA of both nanoparticles and bacteria are playing major roles in their inter reactions and influencing and affecting factors of ZOI. The present study reveals that apart from the SSA of them, the interferences, bio-chemical reactions and affinity of metal nanoparticles with cell wall/fluid of microbes are also one of the main factors.

Exposure of bacteria cell to the environment and rate of exchange of substances that is in contact with its surroundings depends on the SSA of bacteria. E. coli shows same exposure to the environment/surroundings in which lead and silver nanoparticles are existing. The SSA of lead nanoparticles is more than silver nanoparticles. It means lead nanoparticles have more reactive sites than silver nanoparticles. Also, due to its lesser size, it can easily enter into the E.coi cell more than silver nanoparticles while $E$. coli exchanging the surroundings substances.

These factors are supporting for the reactions between lead nanoparticles and $E$. coli but there is no bio-chemical reactions between them or very less reactions while on using more concentration of sample and it is opposite, in the case of silver nanoparticles. The more bio-chemical reactions/interferences between silver nanoparticles and E.coli produce unfavourable surroundings results in more damages to bacteria and increased Zone of Inhibition.

\section{Conclusions}

We have synthesized rod and spherical shaped $\mathrm{Pb}$ nanopowder by electrolysis using a bioactive compound- konjac aqueous extract. The synthesized lead powder has potential applications and can be used in many diverse industries. This synthesis method is a unique, novel and double-step procedure with good reproducibility.

XRD confirms that the prepared nanoparticles are lead which agrees with EDS analysis. The approximate size calculated from XRD is $8 \mathrm{~nm}$ which corroborates with the size $10 \mathrm{~nm}$ assessed from TEM. The size $55 \mathrm{~nm}$ is observed from Particle Size Analyzer. The spherical shape is observed from TEM. The result of SEM gives a conclusion about the rod shape of the synthesized nanoparticles. The melting point observed from DSC is well agreement with the lead nanoparticles of earlier report. AAS result concludes that absorbance of the sample is equal to the absorbance of the standard lead solution. FTIR confirms binding of biomolecules with lead nanoparticles. Anti-bacterial assay of lead nanoparticles against $E$. coli shows that lead nanoparticles act like an inert material and show mild activity when using large quantity.

An attempt has been made to find the effects of the sunlight on nanomaterials which concludes that the sunlight can be utilized for dual function i.e. as a dryer for the synthesized nanomaterials and as a morphological changer. It also explicates that it is possible to change the shape of $\mathrm{Pb}$ nanoparticles (konjac extract added) from spherical to rod by the influence of sunbeams, even after completion of the entire synthesis process.

\section{Acknowledgements}

The authors express their immense thanks to Central Electrochemical Research Institute, (CECRI, Karaikudi), Karunya University (Coimbatore), Indra Gandhi Centre for Atomic Research (IGCAR, Kalpakkam), The Standaard Fireworks Rajaratnam College for Women (Sivakasi), Ayya Nadar Janaki Ammal College (ANJAC, Sivakasi) for providing laboratory instruments to analyze the samples, Dr.S.Amirthapandian of IGCAR for his assistances and valuable guidances in TEM analyses and to Dr.M.Palanivelu, of Arulmigu Kalasalingam College of Pharmacy (Kalasalingam University, Krishnankoil, India) for assistances in anti-bacterial studies. They also acknowledge assistances and encouragements of staff \& management of PACR Polytechnic College, Rajapalayam, India and ANJAC (Sivakasi, India).

\section{Appendix A. Supplementary data}

Supplementary data associated with this article can be found in the online version at the link at: http://nanobe.org/index.php?journal=nbe\& page $=r t \& o p=$ suppFiles\&path []$=218 \&$ path []$=0$

\section{References}

1 Okitsu K., Yue A., Tanabe S., Matsumoto H., Yobiko Y. Formation of colloidal gold nanoparticles in an ultrasonic field: control of rate of gold(III) reduction and size of formed gold particles. Langmuir. 2001; 17(25): 7717-7720.

2 Mallick K., Wang Z.L., Pal T. Seed-mediated successive growth of gold particles accomplished by UV irradiation: a photochemical approach for size-controlled synthesis. J. Photochem. Photobiol. A: Chem. 2001; 140: 75-80.

3 Mafune F, Kohno J, Takeda Y, Kondow T. Formation of gold nanonetworks and small gold nanoparticles by irradiation of intense pulsed laser onto gold nanoparticles. J. Phys. Chem. B. 2003; 107 (46):12589- 2596. 
4 Henglein A. Radiolytic preparation of ultrafine colloidal gold particles in aqueous solution: optical spectrum, controlled growth, and some chemical reactions. Langmuir. 1999; 15 (20): 6738 -6744.

5 Yang S., Wang Y., Wang Q., Zhang R., Ding B. UV irradiation induced formation of Au nanoparticles at room temperature: The case of pH values. Colloid Surface A. 2007; 301: 174-183.

6 Anjali P. Photochemical synthesis of gold nanoparticles via controlled nucleation using a bioactive molecule. Mat.Letters. 2004; 58: 529-534.

7 Weaver S., Taylor D., Gale W., Mills G. Photoinitiated reversible formation of small gold crystallites in polymer gels. Langmuir. 1996; 12(20): 4618- 4620..

8 Miranda O.R., Ahmadi T.S. Effects of intensity and energy of CW UV light on the growth of gold nanorods, J. Phys. Chem. B. 2005; 109 (33): 15724-15734.

9 Esumi K., Matsuhisa K., Torigoe K. Preparation of rod like gold particles by UV irradiation using cationic micelles as a template. Langmuir. 1995; 11(9): 3285-3287.

10 Esumi K., Suzuki A., Aihara N., Usui K., Torigoe K. Preparation of Gold Colloids with UV Irradiation Using Dendrimers as Stabilizer. Langmuir. 1998; 14 (12): 3157-3159.

11 Prakash A., Sharma S., Ahmad N., Ghosh A., Sinha P. Bacteria mediated extracellular synthesis of metallic nanoparticles. Int.Res.J. Biotech. 2010; 1(5): 71-79.

12 Mandal S., Phadtare S., Sastry M. Interfacing biology with nanoparticles. Curr. Appl. Phys. 2005; 5(2): 118-127.

13 Sastry M., Ahmad A., Islam Khan M., Kumar R. Biological synthesis of metal nanoparticles using fungi and actinomycetes. Curr. Sci. 2003; 85(2): 162-170.

14 Sahu K.G., Khadabadi S.S., Bhide S.S. Evaluation of in vitro antioxidant activity of Amorphophallus campanulatus (roxb.) ex blume decne. Int. J. Chem. Sci. 2009; 7(3): 1553-1562.

15 Nataraj H.N., Murthy R.L.N., Setty S.R. Invitro quantification of flavonoids and phenolic content of suran. Int. J. Chem. Tech. Res. 2009; 1(4): 1063-1067.

16 Singh D.P., Srivastava O.N. Synthesis of micron-sized hexagonal and flower-like nanostructures of lead oxide by anodic oxidation of Lead. Nano-Micro Lett. 2011; 3(4): 223-227.

17 Henglein A. Chemisorption effects on colloidal lead nanoparticles. $J$. Phys. Chem. B. 1999; 103 (43):9302-9305.

18 Lee G., Choi S.I., Lee Y.H., Park J.T. One-pot syntheses of metallic hollow nanoparticles of tin and lead. Bull. Korean Chem. Soc. 2009; 30(5):1135-1138.

19 Irshad A., Wani A., Ganguly J.A., Ahmad T. Silver nanoparticles: ultrasonic wave assisted synthesis, optical characterization and surface area studies. Mater. Lett. 2011; 65(3): 520-522.

20 Ghosh S.C., Thanachayanont C., Dutta J. Studies on Zinc sulphide nanoparticles for field emission devices. The 1st ECTI Annual Conference (ECTI-CON 2004), 2004, May13-14; p.145-148.

21 Nehru LC, Swaminathan V, Sanjeeviraja C. Photoluminescence studies on nanocrystalline Tin oxide powder for optoelectronic devices. American J.Mat.Sci. 2012; 2(2): 6-10

22 Sirdeshmukh D.B., Sirdeshmukh L., Subhadra K.G. Micro- and macro-properties of solids: thermal, mechanical and dielectric properties. Springer, NewYork. 2006

23 Chinh N.Q., Gubicza J., Langdon T.G. Characteristics of facecentered cubic metals processed by equal-channel angular pressing. $J$. Mater. Sci. 2007; 42(5): 1594-1605.
24 Weertman J.R. Hall-petch strengthening in nanocrystalline metals. Mater. Sci. Eng. A. 1993;166(1-2): 161-167.

25 Subbaiah Y.P.V., Prathap P., Reddy K.T.R. Structural, electrical and optical properties of $\mathrm{ZnS}$ films deposited by close-spaced evaporation. Appl. Surf. Sci. 2006; 253(5): 2409-2415

26 Velumani S., Mathew X., Sebastian P.J., Narayandass S. K., Mangalaraj D. Structural and optical properties of hot wall deposited CdSe thin films. Solar Energy Materials \& Solar cells. 2003; 76(3): 347-358.

27 Sing P., Kumar A., Kaushal A., Kaur D., Pandey A., Goyal R.N. In situ high temperature XRD studies of $\mathrm{ZnO}$ nanopowder prepared via cost effective ultrasonic mist chemical vapour deposition. Bull. Mater.Sci. 2008; 31(3):573-577.

28 Theivasanthi T., Alagar M. Electrolytic synthesis and characterizations of silver nanopowder. Nano Biomed. Eng. 2012; 4(2): 58-65.

29 Huijmans J.P.P., Ceramics in solid oxide fuel cells. Curr. Opinion Solid State Mater.Sci. 2001; 5(4):317-323.

30 Xubin P., Ramirez I.M., Ray M., Liu J.B. Nanocharacterization and bactericidal performance of silver modified titania photocatalyst. Colloids and Surfaces B: Biointerfaces. 2010;77(1): 82-89.

31 Theivasanthi T., Alagar M. An insight analysis of nano sized powder of Jackfruit seed. Nano Biomed. Eng. 2011;3(3):163-168.

32 Chen J., Li Y.L., Wang Y., Yun J., Cao D. Preparation and characterization of zinc sulfide nanoparticles under high-gravity environment. Mat. Res. Bull. 2004; 39(2):185-194.

33 Jiji A., Joseph N., Donald R.B., Daniel M., Amit S., You Q. Sizedependent specific surface area of nanoporous film assembled by core-shell iron nanoclusters. J. Nanomater. 2006; 2006(54961):1-4.

34 Jo-Yong P., Yun-Jo L., Ki-Won J., Jin-Ook B., Dae J.Y. Chemical synthesis and characterization of highly oil dispersed $\mathrm{MgO}$ nanoparticles. J. Ind. Eng. Chem. 2006; 12(6): 882-887.

35 Alok S., Tsai A.P. Melting behaviour of lead and bismuth nanoparticles in quasicrystalline matrix - The role of interfaces. Sadhana. 2003; 28(1\&2): 63-80.

36 Alagar M., Theivasanthi T., Kubera Raja A. Chemical synthesis of nano-sized particles of Lead oxide and their characterization studies. J.of App.Sci. 2012; 12(4): 398-401.

37 Theivasanthi T, Venkadamanickam G, Palanivelu M, Alagar M. Nano sized powder of Jackfruit seed: spectroscopic and antimicrobial investigative approach. Nano Biomed.Eng. 2011; 3(4): 215-221.

38 Das S.K., Das A.R., Guha A.K. Gold nanoparticles: microbial synthesis and application in water hygiene management. Langmuir. 2009; 25(14): 8192-8199.

39 Lin Z., Wu J., Xue R., Yong Y. Spectroscopic characterization of $\mathrm{Au}^{3+}$ biosorption by waste biomass of Saccharomyces cerevisiae. Spectrochim Acta A. 2005; 61(4): 761-765.

40 Joglekar S., Kodam K., Dhaygude M., Hudlikar M. Novel route for rapid biosynthesis of lead nanoparticles using aqueous extract of Jatropha curcas L. latex. Mat. Lett. 2011; 65: 3170-3172.

41 Muruganantham S., Anbalagan G., Ramamurthy N. FTIR and SEMEDS comparative analysis of medicinal plants, eclipta alba hassk and eclipta prostrata linn. Romanian J. Biophys. 2009; 19(4): 285-294.

42 Shan S., Guo A., Habibi-Nazhad B., Melania R., Paul S., Michael E., David S.W. The CybereCell Database (CCDB): a comprehensive, self-updating, relational database to coordinate and facilitate in silico modeling of Escherichia coli. Nucleic.Acids Res. 2004; 32: 293-295.

Copyright:(c) T. Theivasanthi and M. Alagar. This is an open-access article distributed under the terms of the Creative Commons Attribution License, which permits unrestricted use, distribution, and reproduction in any medium, provided the original author and source are credited. 